\title{
THE WORLDVIEW OF PHENOMENOLOGY
}

\author{
Steven James Bartlett
}

An invited High Table Address given before the students and faculty of Raymond College, University of the Pacific, Stockton, California, December 10, 1969

\section{INTRODUCTORY COMMENTS, NEARLY A HALF-CENTURY LATER}

Raymond College was an unusual experiment in American higher education, one that unfortunately was not to endure. I learned of the school thanks to the interest that Robert Maynard Hutchins took in my education. He was then the head of the Center for the Study of Democratic Institutions in Santa Barbara. Hutchins admired the poetry of my mother, American poet Elizabeth Bartlett; it was she who introduced me to Hutchins, toward the end of my sophomore year as a student in the Honors Division of the University of Santa Clara. Hutchins described to me the unique curriculum that was being offered by Raymond College, begun in 1962 and in its second year of operation. He urged me to give education at Raymond a try.

Raymond College was a "cluster college" established by the University of the Pacific. The College offered a privileged, Oxford-style, close-community environment for learning, an extremely small faculty-to-student ratio, with many of the faculty living on campus in the student dormitories, an academic year consisting of three full-length semesters, and a bachelor's degree obtainable in three years upon passing several days of comprehensive exams. The program of study consisted of some 27 courses, 22 of these required. Classes were very small, often consisting of half a dozen students or fewer; independent study courses, i.e., tutorials, were common and permitted a student to develop a certain level of specialization within a curriculum focused on the liberal arts.

Because Raymond's curriculum was unusual, no transfer students had been allowed into its tailored program of study. But the administration wished to test whether this was feasible in order to replace students lost to attrition; I was chosen as a suitable guinea pig; and I joined 38 other students in Raymond's first graduating class of 1965.

By the increasingly politically correct late 1970s, Raymond College was perceived as elitist, and it was undeniably very expensive to operate and for students to attend. As with many attempts to reach for ideals during humanity's history, the great and insistent waters of normality and mediocrity would soon rush in, inundate and sink the College, and leave in its place a placid lake with barely a ripple to mark what had happened here. 
But during its brief existence, in the very British "High Table" tradition, Raymond's small community of students and faculty dressed for a weekly dinner at white linen-covered tables seating six, served by smartly suited waiters, after which they were addressed by such guest speakers as concert pianist Karl Ulrich Schnabel, science fiction author Arthur C. Clarke, Black Panther attorney Charles Garry, and, in late 1969, me, having graduated there only four years earlier.

I read the paper that follows to the High Table audience, and then answered questions. This was a very long time ago, but I can still feel the sensation of innocence in the new role of public speaker, and can only smile today at the naiveté and impressionism of the paper I chose to give, and for which I make no apology today. I had yet to learn the required cognitive habits and take up the burdens of a professional philosopher - to be ever-socautious, circumspect, and technically sophisticated - and so was still perhaps able to suggest how a philosophical approach could lead to an actual, lived, worldview. - This was, after all, the idealistic 60s, when the study of philosophy could conceivably be thought to lead to the development of a rationally compelling worldview.

May, 2017

The author has chosen to issue this paper as a free open access publication under the terms of the Creative Commons Attribution-NonCommercial-NoDerivs license, which allows anyone to distribute this work without changes to its content, provided that both the author and the original URL from which this work was obtained are mentioned, that the contents of this work are not used for commercial purposes or profit, and that this work will not be used without the author's or his executor's permission in derivative works (i.e., you may not alter, transform, or build upon this work without such permission). The full legal statement of this license may be found at

http://creativecommons.org/licenses/by-nc-nd/4.0/legalcode

(c) $\underset{\mathrm{EY}}{\mathrm{N}} \mathrm{\textrm {NO }}$

C 2017 Steven James Bartlett 
The World-view of Phenomenology

Steven Bartlett

"I consider reality to be the thing one need concern oneself about least of all, for it is, tediously enough, always at hand while more beautiful and necessary things demand our attention and care. Reality is that which one must not under any circumstances worship and revere, for it is chance, the refuse of life. And it is in no wise to be changed, this shabby, consistently disappointing reality, except by our denying it and proving in the process that we are stronger than it." - Hermann Hesse: "My Life: A Conjectural Biography"

It is frequently to be heard today that we live in a time when our values have become unstable, a time when a dead God was buried in a grave dug by technology, a time of uncertainty and confused protest. Time and again there have been such periods of directionlessness in our past; most of us face at least once in our lives a parallel period of doubt.

There is not much point in spending time to discover what beliefs or institutions have failed us; I would prefer to share with you a potential, positive solution to these problems. The solution I will propose attempts to clarify the nature of some of these very human dilemmas, and to indicate possible means for overcoming these dilemmas. In no wise do I see this solution as standing alone in opposition to other ways

* P. 67 in Modern Writing, No. 2 , ed. Wm. Phillips and Philip Rahv (NY: Avon Publications 1954), pp. 55-72. Written in 1924 when Hesse was 47 ; first published in German in 1925. 
of providing a reliable foundation for our values. It often proves possible to examine critically alternate solutions and to render them better applicable to our lives through an examination of the sort I will describe.

\section{The Phenomenological Method.}

It has been my belief that it is the task of the educated person to take to heart the path we find described by Descartes and, earlier, in his own way, by Plato. To follow this path means to adopt as your own ultimate arbiter your own reasoned judgment. Usually, this path seems to involve circuitous detours through involved ideas. And, usually, the technological man cannot spare the time to think out his own way, and, bit by bit, to build a residence of values and ideas unique and organic to himself.

The path described by Plato and Descartes, however, is not clear-cut; neither is it subject to scientific verification. If this statement is felt to point out shortcomings in their approaches, then probably any more or less intuitive approach will be felt inadequate in the same measure.

If a scientific standpoint is desired, then consistency and verifiability become standards which replace that of intuitive certainty. Edmund Husserl, a German mathematician and philosopher who died in 1938, laid the foundations for such a scientific discipline. Its fundamental character remained in agreement 
with what Descartes and Plato believed to be the direction intelligent men must follow. Husserl attempted to make their approach scientifically effective.

He demanded that concepts basic to our theories of theories and theories of action be thoroughly and rigourously explored. Such a thorough exploration, be felt, necessarily precedes thorough understanding. It requires that the investigator bring no assumptions to his work which he cannot show to be evident or to be deducible from other presuppositions which are evident. The methodology which Husserl developed to accomplish this purpose proceeds by bracketing or suspending judgment on all matters of fact. Facts concerning the world are often subject to restrictions either in space or in time - a fact may be valid only in relation to a restricted region of the universe, or the fact may be accepted as such only in relation to a limited period of time. Factual data, concrete information, and individual examples taken from the world of facts are not reliable for the purposes of this science of science, which Husserl calls 'phenomenology'.

Together with assumptions grounded in fact, prejudices and theories relating to the natural world are to be bracketed. Views pertaining to the world as it is naively and unquestioningly accepted are to be set aside as unreliable for the purposes of phenomenology. Among these naive doctrines are those which have to do with our everyday thoughts and feelings concerning the 
physical world and other people. For example, most of us cannot give verification for the notion that objects continue to exist when we do not observe them, for the notion that other: persons are conscious, rather than automatons whose behavior is the sole standard for assessing whether they are conscious beings, and for a whole variety of notions which we are taught, or to which we are day-by-day habituated. These make up the territory of the unquestioningly accepted value or belief; obscurity on this most basic level of theory is the father to confusion on the level of daily existence.

With these naive assumptions out of the running, phenomenology proceeds by investigating any concept or object from the standpoint of those conditions which must be granted, and without which the concept or object becomes impossible. It is at this point that phenomenology becomes somewhat obscure, so let me try to clarify: In chemistry, molecular structure is studied with an eye to what elementary forms of matter are necessary to produce the molecular structure in question. The natural sciences, taken in general, attempt to study phenomena with an end to discovering the most fundamental principles governing the structure of those phenomena and their behavior in a variable environment. Phenomenology, on the other hand, would attempt to bring to light the principles involved when the possibility of a given phenomenon is thrown into question. Phenomenology performs analyses on the level of the possibility of the phenomenon, while the natural 
sciences undertake to understand the phenomenon on the level of its given, factual and general structure. Note that the conditions which must be granted in order to provide for the possibility of a given phenomenon, will at once be those conditions underlying the investigation of that phenomenon from the standpoint of the natural sciences. It is for this reason that phenomenology was characterized by Husserl as the science of sciences, or the theory of theories.

All of this is somewhat abstract, and is made obscure because of the difficulty of giving quickly intelligible illustrative examples in which this description of phenomenology. is made concrete. It is similarly difficult for a quantum physicist to illustrate his approach by holding up an energypacket.

Philosophy sometimes has functioned as a spokesman for common sense, and, where this claim is weakened, it is acceptable to most people that philosophy is accessible to the layman, as are some novels and some poetry. To date, phenomenology has remained a part of philosophy, although there appears to be considerable interest on the part of science departments to include courses in, for example, the phenomenological foundations of physics, biology, mathematical logic, and linguistic theory. Something may be gained here through a rough comparison with research on the quantum level. Several of the tentative conclusions of quantum mechanics run counter to common sense; at times, the results are strikingly odd, while being difficult 
if not impossible to accomodate to our everyday conceptual scheme.

The unexpected is increasingly encountered on the borders of scientific research, and for phenomenology, the same has been the case. Results of some researchers have been distinctly counter-intuitive, while the validity of these conclusions remains unaffected by this fact, except perhaps for fundamentalists.

The intuitive cannot in itself provide a helpful guideline. We are already adrift, and outworn charts are ineffective. Phenomenology remains open to surprise, and to do so, the old charts are pushed aside.

What, then, for Husserl guides phenomenological research? He sets up rigourous standards for classification, for logical consistency, and for scientific method. He provides us with a model which functions to express distinctions between different kinds of phenomena, and marks with precision the conditions of possibility of these groups or regions of phenomena. Yet, in the last analysis, he finds it necessary to appeal to that which is intutitively evident.

In my estimation, this consitutes a breach of his original contract with scientific method. Yet I greatly respect his intensive studies and desire for rigour. I do not wish to condemn his approach, but rather to find what is valid and useful in it, and suggest my results to you. 
II. De-projection as a refinement of phenomenological method.

As you have seen, phenomenology as it was developed by Husserl proceeded through a straightforward dismissal of naive views as fundamentally unreliable. The standard for a nonnaive view became roughly that of intuitive evidence. But what is intuitively evident as inconceivable today may become tomorrow's commonplace. The transition from Newton to Einstein, or from Euclid to Riemann and Lobachevsky, is a case in point.

To overcome this scientific inadequacy in phenomenological method, the matter can be approached from another side. Rather than rejecting a theory because naive, a logically sound method can be developed to deal with such theories in order to explore their theoretical acceptability. It would be unfair to some of you merely to list here the results of my research; on the other hand, I cannot, in all fairness, burden you with a great deal of technical machinery. And so I will outline briefly a refinement of phenomenological method which attempts to bring the discipline into the scientific arena.

Expressions in a natural language are essentially relative to a specific region of discourse. Similarly, a form of relation in mathematical logic or a sign or symbol of formal language is relative to particulars related in the given manner, or to a definite formal system. Objects in general are relative to a given frame of reference. A concept is relative to a given 
universe of meaning. An identifiable phenomenon of whatever kind is relative to a determinable region of identification. Etc. In general, it is possible to characterize any phenomenon or theory in relation to other phenomena or theoretical entities to which the phenomenon or theory is essentially relative. In this way, the conclusions of a non-euclidean geometry are essentially relative to that particular system of geometry for their sense and truth-value The patterns of relativity are to be found in every discipline; the network of relativistic relations constitutes or provides the foundation for a discipline's internal unity.

An analysis of these kinds of relations can yield some interesting results: it can be demonstrated that if two things are connected by a relation of essential relativity, then to affirm one out of connection to the other is logically inconsistent. As an example, consider a Cartesian coordinate system simply as a certain kind of system which permits definite means for identifying the position of objects in terms of an ideal origin in the framework. An object, the Cartesian coordinates for which are given, is represented in such a way that its position can be located in a Cartesian coordinate system. If these coordinates are thought to locate the object from the standpoint of a Polar coordinate system, a conceptual misconstruction results. By a 'conceptual misconstruction', I mean a logically invalid proposition resulting from an improper

* or to any system relative to which these conclusions are significant and provable. 
operation with a set of conceptual structures'. The particular type of conceptual misconstruction which is of significance here is termed a 'projective misconstruction', or, more simply, a 'projection'.

A projection is a conceptual misconstruction which, when it is analyzed explicitly, comprises an apparent severing of the relativistic relations essential to the possibility of reference to a given object. In other words, a projective misconstruction would attempt to disconnect two things which are essentially relative to one another, where this essential relativity of the one to the other is necessary in order for either to be possible. Without this relation of relativity, the two objects are impossible. They are "impossible" in the sense in which it is impossible for two contradictory propositions simultaneously both to be true. A projection fundamentally involves a selfcontradiction, and for this reason is considered logically invalid.

Now, a method can be developed which enables us both to bring to light projective misconstructions of which we are ignorant, and to avoid using concepts or theories which are projective in nature. This method is termed 'de-projection', since it would eliminate projective misconstructions.

Recall that in Husserl's phenomenology, naive views are dismissed as intuitively unreliable. It turns out that many, if not all, of the naive views about which Husserl suspends 
judgment are also projective in the sense just mentioned. Each of these views can, by means of the method of de-projection, be shown to be internally inconsistent. They include our everyday ideas of our selves, of other persons, of time and space, of the nature of truth and causality, - in short, it would seem that a fundamental revision must be undertaken in our view of the world if we wish to hold to a rational world-view.

At this point, I should like to outline some of the necessary revisions to which intelligent thinking must become accustomed.

III. Reality for phenomenology.

A question normally elicits three possible clear-cut replies: an answer which is either true, or false, or simply irrelevant. When the question can be shown to be meaningless, replies to the question are meaningless, too. To answer a meaningless question is to speak nonsense. However, it has been correctly noted by some authors that to say of a meaningless question that it is meaningless, is not a meaningless statement.

De-projection attempts to show whether a view is meaningless, and it attempts to salvage from such views what is not logically inconsistent about them. Once the inconsistency involved in asking a certain question is demonstrated, the set of answers to that question is likewise rejected as inconsistent.

It is not uncommon, then, to have the following situation 
come about: A question is asked, for example, 'How many sides does a round square have?' The question is shown to be senseless, since a 'round square' is a contradiction in terms. Whatever answers have been suggested to the question are marked as logically irrelevant: the the round square has four round sides, that it has an infinite number of sides, or that it has no sides at all. All the answers are meaningless answers to a meaningless question. And, to make matters more complex, none of the answers are true, and none of them are false. Is it true or false that there are many married bachelors?

The same situation arises when a projection is encountered. A projection may be thought of as a meaningless answer given to a meaningless question. If a question is shown to be without meaning, then neither a given answer to the question nor its negation can be true. Neither can they properly be called 'false'. Consequently, projections are neither true nor false, but, for the purposes of phenomenology, are so much non-logical chaff.

It will complicate matters enormously if I give you adequate proofs that what I shall claim to be projective views truly are. You may either take my word for it, or we can talk about it later. What I am concerned to do here is to indicate some of the critical and projective issues wo base our lives on, and then attempt de-projectively to separate the grain from the chaff and suggest what some of the real questions are. 
If de-projection is thought of as an attempt to put phenomenology on a more rigourous scientific footing, then it is understandable that where a view is demonstrated to be projective, it will also prove to be an unverifiable view. However, not all views which are unverifiable are projective, as well. I suggest the criterion of unverifiability merely as an occasionally helpful indication of a projective misconstruction.

To articulate a world-view, a stand is usually taken, in one way or another, expressly or tacitly, with regard to various issues. Among these are to be found the concept of an enduring world, the distinction between subjective and objective reality, the notion of self-identity through time, the relation: between the ' $I$ ' and others, the nature of space and time, and the nature of the relation between events in space and time. It is my contention that not one of these basic, everyday issues has behind it a non-self-contradictory structure. If it is true that each one of these issues has been the occasion for inconsistency, then it is no wonder that there is today an absence of a coherint world-view, of direction, and of rational planning. And it is with little wonder that young people today find it difficult to structure a life-plan and to support that plan with the necessary convictions.

Once fain, I shall grant that the following issues have given rise to views which are projective: the concept of an enduring world, the distinction between subjective and objective 
reality, the notion of self-identity through time, the relation between the ' $I$ ' and others, the nature of space and time, and the nature of the relation between events in space and time. Here, then, is a sketch of the way a de-projective phenomenologist sees the world:

The world is fundamentally astonishing and full of surprises. The world comes and goes in steady correlation with the wakesleep cycle. Experience is the fabric of the world, a world which comes into being in fits and starts, which is daily subject to unexpected transformation. Time is expressed in the connectivity between sequences, while space is a more complex organization which includes time as an aspect of order. Time and space are forms of order which have a common foundation in the space-time manifold of experience. Events in this manifold which are related in continuous correlation are said to be causally related.

The manifold of experience, like the finite universe without boundaries of relativity physics, is finite and without limits. There is no "outside" or "inside" relative to experience, but experience expands continuously through life. History and the past are structures of the present, and their "existence" is only in relation to what is now. Expanding experience is at once an expanding of the past.

To awaken in the morning and find the same world, the same people, the same ' I', is remarkable, and possesses the 
same quality of oddness that uncaused events at the quantum level at present appear to have. This continuity about experience soon becomes familiar, so that to take note of it seems itself strange.

This amazing solidity in the midst of change and growth we normally are ignorant of or gloss over. The structure of the world is intricately tied to that of consciousness; yet will a man lose the latter in war to save the former. For the phenomenologist, there is a great deal of truth in the inversion, "If life is worth dying for, it is worth living for?.

But this kind of description has more literary or personal interest than it does scientific. It is helpful to separate out some of the more important attitudes which are implicit in the world-picture of the de-projective phenomenologist. The cyclic character of the world is acknowledged, along with the fact that no cause of the cyclic character of the world is discoverable. Causality is a useful concept in dealing with events in the empirical world, but the application of the concept is essentially relative to such events in the world. To ask if the world ultimately has a cause "outside" the world is projective. The concept of "having-an-outside" is relative to spatial things, and space is a form of order of things in the world. Areas or volumes have outsides only in connection with other areas or volumes 
in the world. Concepts essentially relative to this world cannot be taken out of relation to the world. To attempt to do so involves inconsistency and nonsense. Whether the cyclic character of the world ultimately has a cause is a meaningless question.

Physical laws are descriptions of empirical correlations, but these laws are only descriptive of the past; they have no necessary future predictive value. Their practical predictive value is dependent upon the unlikelihood of possible future discontinuities. Is it out of reason or habit that laws of the future must be the laws of the past? Physics is consequently history.

The future, then, is structured by possibility. The attitude with which the future is encountered must fundamentally be an open one - equally open to novelty as to conformity with the past. This openness also involves the freedom from the view that two contrary statements about the world cannot both be true. Here the world-view of phenomenology accords with a recognition of complementarity in physics.

The system of experience expressing the world is selfenclosed - it is finite, without boundaries. Phenomena are related in experience as the two apparent sides of a Moebius strip. The strip has but one surface, which re-curves upon itself. The closed topological character of the Moebius strip, 
of the Klein bottle, of spherical Riemannian space, express somewhat metaphorically the self-enclosure of the world of experience, which, through its structure, provides the basis for self-reflection, for consciousness of consciousness, to whatever degree.

Experience is topologically closed. Thus the future is expressed in the present. Change is a phenomenon among others, a given, not required by logic. So are human actions phenomena among others. When they are motivated by a desire to initiate change to bring about a situation which "exists" in the future, actions are projective: changes merely come to be; the belief that they are the consequence of human causation, and will be correlated with human activity in the future - that is a projective assumption for which justification must go begging. In this manner is the progressive mentality inconsistent.

The scope for self-actualization is the present; the present is the only non-self-contradictory channel available for the living. Both the existentialism, which has crept out of spiritual disintegration, as well as the spiritualism of the past, have made good use of the concept of death. Experience is given a limit, and an outside is either affirmed or denied beyond that limit.

For de-projective phenomenology, it is meaningless to agree or disagree with a senseless view. The projective view of death provides no meaningful guide for a construction of 
human values. It does not give a basis for choosing a personal direction in life.

Self-identity is essentially related to a recognition of some degree of day-to-day continuity in events. The perspective of the individual is the world. Phenomenological psychiatry is correct, I believe, in acknowledging that neurosis stems from an inadequate comprehension of the structural principles of the life-world, the world in which the individual lives. We are slowly getting away from the notion that neurosis is a deviation from a norn.

Finally, the world-view of the phenomenologist rests upon a difficult kind of detachment which is not acquired, but developed through training. This kind of detachment involves a spectator's comprehension which is, at the same time, participation. Those of you who have studied a musical instrument know something of this detachment if, after practice and repeated failure to master a phrase of music, it comes spontaneously, seemingly without effort. Similarly, we normally speak our native tongue without conscious effort, while we may sometimes be conscious of our own speech process while maintaining a coherent conversation.

In much

/the same way, the world-perspective of the phenomenologist

is ideally disciplined in spectatorial self-reflection while the phenomenologist is actively engrossed as a participant. However, it is not this way of thinking which is unique to the 
phenomenologist, for it is developed in Zen, as well. The distinctive thing with which the phenomenologist concerns himself is possibility, a relatively unexplored region which phenomenology attempts scientifically to explore.

IV. Some remarks on the world-view of phenomenology as a foundation for a philosophy of education.

I should like, in closing, to make a few remarks on the world-view of phenomenology as a foundation for a philosophy of education.

It has probably become clear that a phenomenological ontology admits a plurality of different regions of being. The universe which phenomenology studies is densely populated with different kinds of entities gathered together under the term 'phenomena'. These entities include ideas, mathematical models, expressions in a natural or formal language, physical objects, emotional states, the characters of fiction and history, - in short, whatever can be definitely identified and described.

A philosophy of education usually sorts out these various kinds of entities, and says of some that they are more significant than others. Frequently, the ranking of such priorities in a program of study is admitted unquestioningly; for phenomenology, the logically inconsistent is given low priority. The set of values which its outlook would foster reflects the richness of its ontology. This richness is valued 
most in a liberal education.

Phenomenology would encourage studies which are intended to enable the individual to reach a point where he can maintain his own inspiration to continue the work of developing himself. Phen omenology would tend to discourage studies which lead to projective concerns, for example, political involvement motivated by a desire for progress. In general, its overall concern is twofold: to help the individual acquire the tools for understanding his life-world, and to reinforce the conviction that the development of his world is worthwhile.

V. The relation between the public world and ivory towers.

It is crucial to this task that the relation between the public world and ivory towers be understood. As far as I can see, the term 'ivory tower' has gained a sometimes unfavorable flavor because society has found some ivory towers to be impractical: they are often very beautiful, but remain, nevertheless, useless. But, for what are these towers found to be useless? More often than not, they are found guilty of not being in the best interests of the goal of progress. In this country, the ideal of progress is closely linked with a tradition and an ethic. In America, pure science is quickly giving way to the social, political, or industrial engineer. For him, especially, the ivory tower is a threat. 
The most recent condemnation of "the marginal man", a heading which includes the non-political artist, poet, musician, scholar, and hermit, has been that he is guilty of the crime of silence. That silence is a crime, is a foregone conclusion. It is a foregone conclusion that the ivory tower represents an outmoded value of an outmoded philosophy of education, rather than an expression of the highest and most noble in man. Again, in the words of Hermann Hesse: I consider reality to be the thing one need concern oneself about least of all, for it is, tediously enough, always at hand while more beautiful and necessary things demand our attention and care. Reality is that which one must not under any circumstances be satisfied with, that which one must not under any circumstances worship and revere, for it is chance, the refuse of life. And it is in no wise to be changed, this shabby, consistently disappointing reality, except by our denying it and proving in the process that we are stronger than it."

$$
\text { * * * * * * }
$$

